\title{
O Sujeito na/da Arte Contemporânea: nos entremeios dos discursos da/sobre arte
}

\author{
The Subject of/In Contemporary Art: \\ IN THE IN- BETWEEN OF THE DISCOURSES OF/ABOUT ART
}

Renata Marcelle Lara*

Resumo: Pela categoria da contradição discursiva, este artigo focaliza o sujeito na/da arte contemporânea, do lugar de entremeio de áreas do conhecimento, nos entremeios do discurso artístico e sobre o artístico, como parte das discussões que foram foco da mesa-redonda Discurso da Arte e(m) Discursos sobre a Arte, durante a realização da $3^{\text {a }}$ JIED Jornada Internacional de Estudos do Discurso) e do $2^{\circ}$ EIID (Encontro Internacional da Imagem em Discurso). Objetiva-se, na relação entre Arte e Linguística, do lugar de analista de discurso, problematizar os sentidos possíveis para esse sujeito que se constitui e transita entre a estabilização e o movimento de sentidos nos discursos artístico e sobre o artístico. Como referencial teórico, adota-se a Análise de Discurso (AD) materialista, perspectiva do filósofo francês Michel Pêcheux, em diálogo com estudos empreendidos na Arte, por Anne Cauquelin e, em especial, por meio das relações entre Arte e Psicanálise lacaniana, promovidas por Tania Rivera.

Palavras-chave: Análise de Discurso. Arte contemporânea. Contradição.

Abstract: Working with the discursive contradiction category, in this article we are focusing the subject of/in contemporary art from the space in-between the knowledgement areas. This work is part of the discussions about the inbetween space of the arts discourse and the discourse about arts presented in a roundtable in the $3^{\text {rd }}$ JIED (International Conference in Discourse Studies)

* Doutora em Linguística pela Unicamp (2008). Professora Adjunto C na Universidade Estadual de Maringá (UEM). Contato: renatamlara@yahoo.com.br. 
and 2nd EIID (International Meeting of Image in Discourse). We aim, based in the relation between Arts and Linguistics, from the discourse analyst position, render the possible meanings problematic to this subject that is formed and transits between the stabilization and the meanings movements of the arts discourse and the discourse about arts. This work is based in the materialist Discourse Analysis (DA) of Michel Pêcheux together with Anne Cauquelin arts studies and specially based in Arts and Lacanian Psychoanalysis conducted by Tania Rivera.

Keywords: Discourse Analysis. Contemporary art. Contradiction.

\section{Desdobramentos Iniciais de Uma Abordagem Teórica}

Neste texto, apresento uma abordagem teórico-discursiva, pela perspectiva pecheutiana, acerca do Discurso da Arte e (m) Discursos sobre a Arte, que foi tema de uma das mesas da $3^{\mathrm{a}}$ JIED (Jornada Internacional de Estudos do Discurso) e do $2^{\circ}$ EIID (Encontro Internacional da Imagem em Discurso), realizados na Universidade Estadual de Maringá (UEM), em março de 2015. O recorte que faço do tema da mesa está situado nos territórios discursivos de inquietações acerca da arte contemporânea, que me possibilita esboçar indagações a respeito do sujeito na/da arte, pela categoria da contradição discursiva ${ }^{1}$, em Michel Pêcheux, possibilitando abordá-la como constitutiva do discurso da arte (dizeres da arte/do artístico) e sobre a arte (dizeres acerca da arte e do artístico) em que esse sujeito (é) significa(do).

Antes de ousar tecer qualquer relação entre Arte e Análise de Discurso (AD), e assumir o risco de construir um discurso dispensável frente ao que já foi dito de um lugar de competência discursiva, gostaria de situar que lugar de observação é esse do qual discursivizo a relação entre essas regiões do conhecimento para falar do sujeito na/da arte contemporânea.

Em capítulo do livro $O$ acontecimento do discurso no Brasil, publicado em 2013, que reúne textos discursivos da $5^{\text {a }}$ edição do SEAD (Seminário de Estudos em Análise do Discurso) - e cujo foco temático da discussão resultou

${ }^{1}$ Parto da ideia de contradição como categoria discursiva já como um movimento dos sentidos da categoria de contradição do Marxismo para a Análise de Discurso. 
no título da publicação -, Ferreira (2013a, p. 127, grifos do original) interroga: "O que há em comum entre as três áreas - análise do discurso, arte e psicanálise?". E chama a atenção para o fato de que a resposta dependerá, entre outros, do "lugar de observação" no qual se situa o sujeito que responde. Antes de marcar o seu lugar, destaca que "as três regiões não se situam em espaços logicamente estabilizados", o que já cria, conforme a pesquisadora, uma “cumplicidade a priori". Sequencialmente, já se marcando do lugar do discurso, destaca, de início, dois elementos que situa como primordiais no enlace dessas regiões do conhecimento: "o sujeito e a linguagem”. É desse lugar que organiza seu dizer em torno da interrogação lançada.

O que tem movido minhas apresentações em outros eventos científicos em que áreas se põem em relação é justamente o entremeio discursivo, que não é somatória ou acúmulo, mas metafórico, como transferência ${ }^{2}$. Contudo há uma diferença gritante, a meu ver, de quando me ponho a falar da relação entre Análise de Discurso e Comunicação e o meu dizer em um evento, como é o caso da $3^{a} \mathrm{JIED} / 2^{\circ} \mathrm{EIID}$, em que se põem em relação a Análise de Discurso e a Arte.

Quando estabeleço teoricamente uma relação entre Análise de Discurso e Comunicação, quando sou chamada a falar sobre ou desse lugar relacional, demarco meu lugar de analista do discurso, mas com a possibilidade de me inscrever de dentro da área comunicacional, revisitando-a, tumultuando-a e, assim, a minha própria formação primeira como comunicóloga, mais especificamente jornalista. Daí que a minha formação segunda - termo este que emprego aqui apenas em uma ordem cronológica e hierárquica de titulação, mas não de importância -, como linguista, e de forma bem recortada analista de discurso, permite-me transitar entre as áreas, falando de seus interiores, de um dado interior, que é o discursivo. Também possibilita relembrar Pêcheux (1990) naquilo que marca a minha relação com Delimitações, inversões, deslocamentos, que é justamente pensar na resistência não como oposição, confronto entre lados estanques, mas inscrita no interior do próprio

2 "Nem sobredeterminação, nem instrumentalização, nem aplicação. Uma relação metafórica, ressignificação, como a que se dá quando se toma discursivamente a não transparência do sujeito, a não transparência da língua, a não transparência da história" (ORLANDI, 2012, p. 11). 
movimento, no caso, de dentro de uma área, e que, a meu ver, acontece na relação do dentro com o fora, do fora com o dentro, ou dentro, consigo mesma, seja entre áreas ou em outros domínios do conhecimento.

Previamente a me pôr a falar de Discurso da Arte e(m) Discursos sobre a Arte, num evento de analistas de discurso ( $\left.3^{\mathrm{a}} \mathrm{JIED} / 2^{\circ} \mathrm{EIID}\right)$, voltei a pensar sobre qual seria o meu lugar de observação. Continuava sendo o lugar de analista do discurso. Mas, como me situar em relação à Arte, se esta não faz parte da minha formação acadêmica? Lembrei-me do que disse Eni Orlandi, em sala de aula, quando cursei uma disciplina do Doutorado em Linguística, na Universidade Estadual de Campinas (Unicamp), em 2003, que não precisaríamos ter conhecimento profundo sobre Marxismo e/ou Psicanálise para estudar Análise de Discurso. O fato de conhecermos estudos específicos acerca de tais saberes poderia ser favorável à nossa compreensão da teoria e do método discursivos, mas não determinante ou indispensável, porque a Análise de Discurso já era outra coisa, outro conhecimento, outra disciplina, e não uma somatória entre Linguística, Psicanálise e Marxismo. O que nos interessa é aquilo que do Marxismo e da Psicanálise, em termos de deslocamento, funcionam na Análise de Discurso e como Análise de Discurso.

Não tendo formação em Arte, mas compreendendo, do lugar de analista do discurso, a possibilidade de se dizer sobre e permitir o dizer de um dado lugar, é que demarco o meu lugar do dizer a respeito do recorte temático proposto neste texto. E o meu lugar é de alguém que se assume analista de discurso, teórica e metodologicamente, com todos os conflitos, instabilidades e incertezas que isso significa, e que se inseriu ou foi inserida, por força da profissão docente e, posteriormente, pelo prazer da descoberta, nos territórios das Artes Visuais. É dessa experiência como docente de disciplinas de metodologia da pesquisa em Artes Visuais e analista de discurso que me proponho a desenvolver o recorte temático acerca do sujeito da/na arte contemporânea nos entremeios dos discursos da arte e sobre arte, problematizando, pela categoria da contradição discursiva, os sentidos possíveis para ele nesse e desse lugar. 


\section{Lugares Sociais e Efeitos Discursivos a Respeito da Arte}

Quando eu me referi ao fato de a resistência acontecer do interior do próprio movimento, na seção anterior, é porque compreendo que não se pode combater o discurso do outro sem que se conheça esse discurso de seu interior. É assim que penso as metodologias de pesquisa: não como universais, mas em suas especificidades, construídas na área, dentro dela.

Um dia, quando me preparava para trabalhar as metodologias de pesquisa em Artes Visuais, no interior dessa área deparei-me com as seguintes afirmações: "A arte não é discurso, é ato. A obra se elabora através de gestos, procedimentos, processos, que não passam pelo verbal e não dependem deste. Seu instrumento é plástico". Logo, “o que resulta é um objeto, presente em sua fisicalidade, independente de todo e qualquer discurso, inclusive, do próprio artista”. E mais: “Talvez o grande equívoco de análise, nas últimas décadas, tenha sido considerar a arte como uma modalidade específica de discurso”. Por fim, “é por seu caráter 'não-discursivo' que a arte pode acolher uma pluralidade de discursos. Todos poderão ser válidos, mas nenhum a "traduzirá" (CATTANI, 2002, p. 37, grifos do original).

Tais afirmações foram reunidas em um capítulo do livro $O$ meio como ponto zero: metodologia da pesquisa em Artes Plásticas, publicado em 2002, como resultado do III Colóquio Internacional de Artes Plásticas, sediado na Universidade Federal do Rio Grande do Sul (UFRGS).

Minha primeira reação foi de surpresa à afirmativa da autora e certo estranhamento, já que eu vinha me identificando com outras escritas dela a respeito da arte contemporânea. Entendo que tanto ela quanto eu fomos interpeladas ideologicamente. No meu caso, ao buscar problematizar as bases de sustentação das Artes Visuais, esqueci-me de um fundamento da Análise de Discurso, que está em problematizar as suas próprias bases de sustentação. Afirma Pêcheux (1997c, p. 179, grifos do original):

... todo 'ponto de vista' é o ponto de vista de um sujeito; uma ciência não poderia, pois, ser um ponto de vista sobre o real, uma visão ou uma construção que representasse o real (um 'modelo' do real): uma ciência é o real sob a modalidade de sua necessidade-pensada, de modo que o real de que tratam as ciências não é senão o real que produz 
o concreto-figurado que se impõe ao sujeito na necessidade 'cega' da ideologia.

Lembrei, então, da relevância discursiva do lugar social de quem enuncia e os sentidos possíveis, apagados, silenciados ou interditados - resultantes de projeções imaginárias (cf. Pêcheux, 1997a) na passagem dos lugares para as posições no discurso - acerca dos termos em áreas e teorias distintas. Para Cattani (2002), discurso funcionava como sinônimo de linguagem verbal oral e escrita. $\mathrm{Na}$ relação com esse sentido, o entendimento dela de que a arte não era discurso, e que não deveria ser reduzida a uma tradução verbal, sustentava-se. Também veio à tona outra discussão próxima suscitada na minha tese de doutorado (PIMENTEL, 2008) ${ }^{3}$-, sustentada em trabalhos de Eni Orlandi (1995, 1997) e Tânia Clemente de Souza (1998, 2001), sobre a problemática da redução da imagem ao verbal e a necessidade de se considerar a imagem como discurso, em sua materialidade própria, e não traduzida pelo verbal.

Na época de elaboração da tese (2003-2007), defendida em fevereiro de 2008, havia dificuldade em se trabalhar a imagem como discurso nos territórios próprios da $\mathrm{AD}$ pecheutiana - e, de certa forma, isso ainda acontece, embora em menor intensidade e confusão -, sendo que determinados pesquisadores entendiam que necessitavam da Semiótica ou de outra teoria e/ou método para dar conta daquilo que, na visão deles, Pêcheux não subsidiava, ou seja, a análise do discurso imagético - por mais que os fundamentos para tal análise se encontrassem presentes em sua obra, mesmo que explicitamente o dizer conduzisse/direcionasse ao verbal.

O meu lugar de/do dizer, portanto, do Discurso da Arte e(m) Discursos sobre a Arte, neste texto, tem a ver com a necessidade de se considerar justamente esses lugares sociais, de modo a se observar a posição no discurso. Como disse anteriormente, meu recorte está nos territórios discursivos da arte contemporânea, na figura do sujeito, que me possibilita esboçar indagações acerca do sujeito na/da arte contemporânea, e na categoria da contradição, que me leva a abordá-la como constitutiva do discurso da arte e sobre a arte.

${ }^{3}$ Sobre a ideia de composição entre verbal e imagem, na perspectiva pecheutiana, também cf. Pimentel (2012). 
Não cabe aqui aprofundar uma discussão acerca do que seja a arte contemporânea, até porque só isso requereria uma temática específica, dada a complexidade da discussão. Situo apenas, sinteticamente, abordagens de quatro autores acerca da arte contemporânea - três deles investigadores que pesquisam propriamente a arte contemporânea, do lugar de entremeio, e um que aborda tal arte na perspectiva do discurso.

Cattani (2007), organizadora do livro Mestiçagens na arte contemporâneamesma autora cujo comentário sobre a negação da arte como discurso me incomodou em seu outro texto ${ }^{4}$-, afirma em relação à arte contemporânea:

Em oposição à pureza, a produção artística contemporânea aceita as contaminações provocadas pelas coexistências de elementos diferentes e opostos entre si, como, por exemplo, a coexistência de imagens e palavras, cujo sentido permanece no entremeio dos dois universos, ressignificando-se, recontaminando-se mutuamente. A unicidade dá lugar às migrações de materiais, técnicas, suportes, imagens de uma obra à outra, gerando poéticas marcadas pela transitoriedade e pela diferença; o único dá lugar, assim, à coexistência de múltiplos sentidos (CATTANI, 2007, p. 22).

Também se questionam outros paradigmas modernos, como "o artista enquanto gênio criador", ideia que vem sendo "substituída pela constatação da posição deste em uma rede, na qual outros atores (curador, colecionador [e eu acrescentaria o antes apenas observador ou contemplador, agora funcionando como co-autor]) ocupam lugares igualmente importantes" (CATTANI, 2007, p. 22-23) - e eu diria, ainda, até indispensáveis.

Cauquelin (2005a, p. 127), por sua vez, entende que, no domínio da arte, encontra-se, atualmente, uma mistura de elementos, sendo que os valores da arte moderna e da chamada arte contemporânea se ladeiam, trocam fórmulas, sem necessário conflito aberto, como "dispositivos complexos,

${ }^{4}$ Refiro-me à afirmação de Cattani (2002, p. 37, grifo do original), anteriormente citada neste artigo, de que "a arte não é discurso, é ato", e que abre o seu texto intitulado "Arte contemporânea: o lugar da pesquisa", publicado no livro $O$ meio como ponto zero: metodologia da pesquisa em Artes Plásticas, também já mencionado, por mim, há pouco. 
instáveis, maleáveis, sempre em transformação". Ao distinguir arte contemporânea e arte atual, Cauquelin (2005a, p. 129, grifos do original) esclarece que "é atual o conjunto de práticas executadas nesse domínio, presentemente, sem preocupação com distinção de tendências ou com declarações de pertencimento, de rótulos".

Para Noronha (2012, p. 25), o conceito de contemporâneo não está restrito "à maneira conteudista (certos temas, procedimentos e conceitos) de dar tratamento a (sic) arte e a (sic) história da arte contemporânea”. Daí o contemporâneo surgir como "a investigação da problemática e da experiência do tempo”. O que o autor aponta, aludindo à arte e à sua história e, posteriormente, citando nomes de autores que o levaram a pensar sobre isso, como Walter Benjamin, Roland Barthes e Giorgio Agamben, é que "contemporâneo é um conceito" e "atualidade é um modo de localizar no tempo a contemporaneidade" - só que "é também um modo de atualização ou de reconhecimento da presença do passado no presente" (NORONHA, 2012, p. 26). Para mim, o conceito de contemporâneo abarca outra relação com o tempo e o espaço, para além do geográfico e cronológico, tomado pelo simbólico e ideológico.

Nunes (2009, p. 99), pesquisador do discurso com experiência em análise de dicionários, explica que o termo adjetivo "contemporâneo" associado ao termo substantivo "arte" compõe a unidade lexical "arte contemporânea", apresentando-se, portanto, como uma "lexia da língua". Segundo ele, discursivamente, "essa lexia funciona nos processos de nomeação, de definição, de construção de uma memória", não significando simplesmente "“arte' realizada em um tempo atual", e sim "nome que se dá a um movimento artístico específico". Embora a lexia "arte contemporânea" se mostre nos domínios da arte e mesmo da mídia e do cotidiano, conforme Nunes, não é o que acontece com os instrumentos linguísticos.

$\mathrm{O}$ autor observa que, em dicionários de língua portuguesa por ele analisados - Novo Aurélio Século XXI: o Dicionário da Lingua Portuguesa (1999); Dicionário Houaiss da Lingua Portuguesa (2001) e Dicionário da Lingua Portuguesa Contemporânea (2001) -, ausenta-se a lexia "arte contemporânea". Tal lexia, contudo, vai ser encontrada, por ele, na Wikipédia (enciclopédia on-line), que também compõe o seu material selecionado para análise. Contudo, na definição apresentada, "somente a significação temporal é contemplada, ou 
seja, aquela que vê a arte contemporânea como um 'período' artístico" (NUNES, 2009, p. 101). Como os dicionários e as enciclopédias têm força na fixação do imaginário social acerca da língua e dos significados possíveis para ela, penso que essa ausência de visibilidade do sentido de "arte contemporânea" para além de uma localização temporal participa da cristalização do pré-construído da arte contemporânea como período histórico artístico.

Voltando à questão da relação entre Arte e outras áreas do conhecimento, como a Linguística e a Psicanálise, é pela noção de sujeito descentrado que a Psicanálise lacaniana se inscreve, a meu ver, como relação necessária e constitutiva no entremeio da Arte e Análise de Discurso. Psicanálise que também não integra a minha formação, mas que advém na Análise de Discurso pela noção de descentramento do sujeito e inconsciente estruturado como linguagem ${ }^{5}$.

Assumo o risco de falar dessa relação de entremeio da Arte e Análise de Discurso, em que a Psicanálise é requerida, do lugar de pesquisadora de AD, professora da Pós-Graduação em Letras e do Curso de Graduação em Artes Visuais da Universidade Estadual de Maringá (UEM), em disciplinas de metodologia de pesquisa. É pelas minhas investidas em tentar compreender essas relações e suas possibilidades de contribuição à pesquisa na área das Artes Visuais, pela abordagem discursiva, e também na Linguística, pelos entremeios com as Artes Visuais, que parto, sequencialmente, das contribuições das pesquisadoras Tânia Rivera, Maria Cristina Leandro Ferreira e Nádia Neckel. Rivera, referendando-se na Psicanálise para compreensão das Artes; Ferreira, da Análise de Discurso para estabelecer relações entre AD, Arte e Psicanálise; Neckel, cujos lugares de formação abarcam a Arte e a Análise de

${ }^{5}$ Ao tematizar sobre "A concepção de sujeito lacaniano: um retorno paradoxal ao cartesianismo", Maluf-Souza (2012, p. 175) esclarece, na perspectiva de Lacan, que "o sujeito não é causa dele mesmo, mas o efeito do Outro, que, enquanto efeito, não significa uma sobredeterminação absoluta, pois o inconsciente, a despeito da determinação, é espaço claudicante e presente". Assim, "na relação do sujeito (ser) com o Outro (sentido), há um real do sujeito". Na condição de "sujeito do insconsciente", o sujeito é "um hiato, uma falta, um nonsense que não o identifica nem à condição de sujeito/ser e nem à condição pura de desejo do Outro". 
Discurso, tendo construído um percurso teórico-analítico acerca do Discurso Artístico (DA).

\section{A Contradição nos Entremeios do Discurso Artístico e Sobre o Artístico}

Neckel (2009, p. 109) pontua a presença do termo "discurso" na teoria da arte e na crítica de arte como "discurso de arte", "discurso sobre arte", "discurso da crítica de arte", e se interroga sobre o Discurso Artístico (DA), "sobre a obra de arte enquanto dizer". Enquanto esses outros discursos ("de arte", "sobre arte" e "da crítica de arte") produzem dizeres a respeito da arte, o dizer artístico, na abordagem materialista da Análise de Discurso, em Michel Pêcheux, é, segundo Neckel (2014, p. 191), um discurso constitutivamente heterogêneo, sendo seus sentidos "produzidos por diferentes posições-sujeito". Dessa forma, em sua formulação conceitual acerca do Discurso Artístico, a autora o apresenta "como, fundamentalmente, polissêmico, tecido no movimento, no deslocamento, na falha, e, por isso, predominantemente lúdico" (NECKEL, 2009, p. 110, grifo nosso).

A pesquisadora explica que

... os sentidos produzidos no interior do Discurso Artístico sejam eles pela via de imagens, de sons, de movimentos ou palavras, são gestos de interpretação de acontecimentos outros que podem estar filiados a diferentes formações discursivas e ainda, produtos de discursos outros. São as características do DA em confronto com as características desses outros discursos que determinarão os efeitos de sentido do artístico reforçando os processos discursivos, predominantemente lúdico e polissêmico, sem, contudo, se fechar ao movimento parafrástico, mas constituindo-se no confronto de um e outro. Esse processo é o que chamamos do acontecimento próprio do DA, é o ponto de tensão entre o mesmo e o diferente, o estranhamento. (NECKEL, 2009, p. 109, grifo nosso).

Quero chamar a atenção é para o fato de que, por mais que o Discurso Artístico esteja fundamentado na movência, isto não é garantia, a meu ver, 
de que todo objeto artístico funcione sempre no e pelo deslocamento como abertura ao simbólico.

O fato é que, historicamente, a arte foi e é baseada em paradigmas, como observado em Zamboni (1993), por mais que, em determinados momentos, a meu ver, tenha-se a ilusão de total liberdade do artista na produção de sua obra e nos sentidos possíveis para ela. $\mathrm{O}$ autor esclarece que, na arte, os paradigmas delimitam a forma de atuação e produção, com regras de conduta, estando a obra de arte condicionada aos paradigmas vigentes na época de seu surgimento.

“A obra 'em si' não existe realmente; ela se diz 'obra' por meio e com a condição de ser posta em determinada forma, de ser posta em (sic) 'em sítio'. Fora do sítio, que a teoria construiu e que as teorizações mantêm vivo, ela não é nada", afirma Cauquelin (2005b, p. 21). Logo, prossegue a autora, "nenhuma atividade - e a arte não escapa a essa condição - pode ser exercida fora de um sítio que lhe dê seus limites, determine os critérios de validade e regule os julgamentos que serão tecidos a seu respeito" (CAUQUELIN, 2005b, p. 21). Em nota de rodapé na mesma página da citação que acabei de trazer, Cauquelin menciona o caso da arte contemporânea parecer "errar "fora de sítio"' (2005b, p. 21) e, por isso mesmo não ter critérios, como se escapasse a julgamentos ditos equilibrados, quando "é justamente essa luta entre um sítio que se tornou muito estreito e a atividade artística que permite a transformação do antigo sítio ou a construção de um novo sítio" (2005b, p. 21).

Considerando, portanto, a relação fechamento e abertura de sentidos, em uma e por uma técnica, movimento artístico, entre outros fatores, eu não posso pré-afirmar que, pelo fato de o Discurso Artístico ser constitutivamente polissêmico ${ }^{6}$, ele funcione sempre pela polissemia como abertura, possibilidade de advir outros sentidos, e não como fechamento - até porque,

${ }^{6} \mathrm{Na}$ linguagem, o processo polissêmico, abertura ao novo, ao diferente, à "multiplicidade de sentidos", é o que possibilita a criatividade, sendo que a instauração do diferente, por meio dela, acontece "na medida em que o uso, para romper o processo de produção dominante de sentidos e na tensão com o contexto históricosocial, pode criar novas formas, produzir novos sentidos", e realizar, portanto, "uma ruptura, um deslocamento, em relação ao dizível” (ORLANDI, 1984, p. 11). 
ele também é administrado dentro de um sítio teórico e do fazer artístico possível para uma determinada época e para determinados artistas e suas criações. Assim também como não posso afirmar que o discurso sobre arte sempre apague, silencie ou interdite o discurso da arte, como discurso artístico, porque o dizer artístico pode extravasar no discurso institucional e legitimado, de forma legítima, mesmo que não reconhecido como tal, funcionando como equívoco: inscrição da língua, que é falha, na história, para significar, como compreende Orlandi (2001).

Dizendo de outra forma, por mais que as propriedades do Discurso Artístico sejam polissêmicas, isso não é garantia de que todo objeto artístico possibilite o deslocamento discursivo. Se fosse assim, poderíamos falar em Discurso Artístico como uma tipologia discursiva, que não demandasse análise para observação de seu funcionamento, porque todos os funcionamentos seriam iguais e sempre propensos à movência. Os tipos advêm de "funcionamentos cristalizados" e "o que caracteriza o discurso, antes de tudo, não é seu tipo, é seu modo de funcionamento”, esclarece Orlandi (2000, p. 85-86). Por isso que ao analista de discurso o que interessa são "as propriedades internas ao processo discursivo” (ORLANDI, 2000, p. 86).

Enquanto funcionamento e não como propriedade discursiva, o Discurso Artístico, da forma como eu compreendo, pode também levar ao fechamento de sentidos, à imposição, à sobredeterminação e mesmo à saturação. O que não significa que ele não carregue em si as propriedades rituais da falha, como todo ritual de linguagem, em que a resistência advenha falhando (n)a interpelação ideológica. E é por isso mesmo que cada análise é uma análise e que conteúdo não é sinônimo de discurso e tampouco o Discurso Artístico funcione fora do ideológico, já que não há como estar fora da ideologia.

Ao abordar, em capítulo do Semântica e discurso: uma crítica à afirmação do óbvio, intitulado "Sobre as condições ideológicas da reprodução/ transformação das relações de produção”, Pêcheux (1997c, p. 147, grifos do original) afirma que a contradição, que constitui a luta ideológica de classes,

... não poderia, levando-se em conta o que acabamos de dizer, ser pensada como oposição de duas forças que se exercem uma contra a outra em um mesmo espaço. A forma de contradição inerente à luta 
ideológica entre as duas classes antagonistas não é simétrico, no sentido em que cada uma tenderia a realizar, em proveito próprio, a mesma coisa que a outra: se estamos precisando esse ponto, é porque numerosas concepções da luta ideológica tomam como uma evidência anterior à luta [...] a existência da sociedade (com "o Estado" acima dela) como espaço, como terreno dessa luta.

Penso a contradição como fundamental no funcionamento discursivo. Compreendo-a, na perspectiva pecheutiana, não como opostos ou lados estanques que se põem em confronto/combate, no sentido de aniquilamento um do outro, mas tal como Lagazzi (2011, p. 279), com base em Pêcheux, "como a impossibilidade da síntese, reiterando a distância entre contradição e oposição". Desta forma, esclarece que Pêcheux (1990) "fala da previsibilidade da oposição e de sua impossibilidade de produzir deslocamento na medida em que se configura como o contrário, apenas na inversão de posições" (LAGAZZI, 2011, p. 279). Também ressalta a importância de se "compreender que a diferença não cabe na oposição e, portanto, estar na diferença não é estar no contrário"

Isso para mim é extremamente significativo para não criarmos resistências a priori, reduzida ao campo da consciência, já que, discursivamente, ela advém de falhas do ritual de linguagem, bloqueios na ordem ideológica, ou concebermos dominação sem resistência, pois "não há dominação sem resistência", afirma Pêcheux (1997c, p. 304), em referência ao "primeiro prático da luta de classes, que significa que é preciso 'ousar se revoltar"'.

Lagazzi (2012), ao se referir à resistência na falha do ritual simbólico, em seu gesto de interpretação de uma citação que faz de Pêcheux (1990)

\footnotetext{
${ }^{7}$ A autora se refere a Delimitações, inversões, deslocamentos (PÊCHEUX, 1990).

${ }^{8}$ Retomo aqui a explicação de Althusser (1978, p. 27, grifos do original), em sua Resposta a John Lewis, quando, em nota de rodapé, se refere à tese marxista-leninista que afirma "o primado da contradição sobre os contrários que se enfrentam, que se opõem" ao por "a luta de classes em primeiro plano". Althusser esclarece que isso quer dizer que "a luta de classes não é o efeito derivado da existência das classes, que existiriam antes (de direito e de fato) de sua luta: a luta de classes é a forma histórica da contradição (interna a um modo de produção) que divide as classes em classes".
} 
acerca disso, esclarece que "a falha no ritual se sustenta na contradição e se mostra nos diferentes modos de a resistência se formular, a equivocidade da linguagem dando movimento aos processos de identificação dos sujeitos" (LAGAZZI, 2012, p. 136).

Cito uma passagem do livro Arte e psicanálise, de Rivera (2002, p. 22) para ilustrar a ideia da contradição que quero focalizar no funcionamento da arte e do Discurso Artístico em um objeto artístico:

A Dalí, que sempre reafirmou enfaticamente a influência do mestre de Viena em sua arte, e aproveitou a ocasião para fazer um estudo do velho psicanalista para um desenho posterior, Freud declara diante da Metamorfose de Narciso: 'Nas pinturas clássicas procuro o inconscienteem uma pintura surrealista, o consciente’. Este comentário significou, para o pintor catalão, a sentença de morte do surrealismo.

Rivera (2002, p. 22) esclarece que "mais do que simples mal-entendidos, os desencontros entre Freud e os surrealistas refletem o fato de a psicanálise sofrer no surrealismo uma torção, uma distorção capaz de criar uma espécie de ficção de psicanálise". A questão é que a Psicanálise, como esclarece Rivera (2002, p. 23), "marcou a arte do século XX", assim como a arte moderna e a contemporânea vêm deixando traços profundos na Psicanálise, mesmo com a reticência freudiana; influência esta tornada sensível com Lacan.

Não se trata aqui de concordar ou discordar da perspectiva freudiana acerca de suas impressões sobre o movimento surrealista ou daquilo que se diz a respeito do que Freud teria dito sobre o Surrealismo. O que quero é enfatizar a relevância da noção de contradição como norteadora de um processo analítico-discursivo, em especial, na relação discurso-arte, artediscurso. Não é porque um movimento, uma escola, corrente, artista ou época pré-defina as características e os fundamentos de uma dada expressão ou objeto artístico que, em termos discursivos, já funcione como tal. Daí a importância da análise, da especificidade de cada percurso, que se faz em curso, em movimento. Como afirma Mariani (2012, p. 58), "o analista de discurso não põe no divã o sujeito", pois isso compete ao psicanalista. O que ele faz é "interrogar, criticar, questionar a produção e evidências nos processos de constituição dos sujeitos e dos sentidos". 


\section{O Retorno do Sujeito na Arte Contemporânea}

Por que o foco no sujeito na/da arte contemporânea, ao me propor a falar do lugar de entremeio de áreas do conhecimento e nos entremeios dos discursos artístico e sobre o artístico, considerando a contradição como uma categoria discursiva? A arte contemporânea é constitutivamente inquieta e inquietante. "O sujeito está no centro da questão da arte", afirma Rivera (2013, p. 20). Mas não mais o sujeito como "olho soberano", ordenador da representação em regras. Trata-se de um sujeito "descentrado", aquele que não coincidente com "um centro organizador" dessa representação.

$\mathrm{Na}$ arte contemporânea, o sujeito que retorna

... problematizou suas fronteiras em relação ao outro, no mesmo passo em que se temporalizou e deslocou em uma nova concepção, fragmentada, do espaço. Contudo, uma vez abandonado seu lugar como origem inequívoca da representação, ele volta de fora da representação, como corpo real - o que reconfigura suas relações consigo próprio, com o objeto e com o espaço. O sujeito recusa-se a se assimilar ao olho ideal e, nesse deslocamento, perde seu lugar de direito para retornar como questão, em uma convocação direta do espectador (RIVERA, 2013, p. 21).

Rivera (2013, p. 21) cita Hal Foster (1996) ${ }^{9}$, para quem o real que retorna na arte contemporânea "é o oposto da realidade mimética", não sendo "realidade como janela para o mundo, dada por e para um olho fixo". E continua:

Trata-se do real do léxico de Lacan, aquele que é uma espécie de fundo último das coisas, destacado da imagem, e que se trata sempre de tentar representar, sem que tal operação jamais se cumpra de forma definitiva. Real traumático, terrível, com o qual o sujeito se depara repetida e violentamente (RIVERA, 2013, p. 21).

${ }^{9}$ A obra citada é The return of the real: the avant-garde at the end of the century. 
Como explicam Baldini e Mariani (2013, p. 112), em Lacan, o real é "efeito do próprio simbólico", “irrepresentável, inomeável”; o que "resiste a ser simbolizado", afirma Borba-Rodegher (2013, p. 115), também com base em Lacan. Na abordagem discursiva do real, nas palavras de Pêcheux (1997b, p. 29), "não descobrimos, pois, o real: a gente se depara com ele, dá de encontro com ele, o encontra". Conforme Borba-Rodegher (2013, p. 118), "o real em Pêcheux difere do de Lacan na medida em que abarca a condição de existência nas noções, ou seja, o que é próprio, o que é da natureza da noção em questão"; o que significa que "a noção de real da língua formulada pelo analista de discurso só se faz possível se for pensada num conceito de língua afetado pelo inconsciente e assujeitado pela ideologia".

Meu foco é para o sujeito na/da arte contemporânea como sujeito discursivo, afetado pelo inconsciente, não absorvido por ele/nele. Sujeito corpo-discursivo, no sentido em que Ferreira (2013c, p. 99) compreende o "corpo discursivo", "materialidade significante", e não como redução ao corpo físico, orgânico. Corpo como "efeito de linguagem", na perspectiva lacaniana, como explica Ferreira (2013c, p. 104), e "efeito de discurso", na abordagem discursiva assumida pela autora.

Para mim, corpo como materialidade constitutiva do sujeito, sua existência material, que permite ao sujeito (se)significar no mundo - o que eu chamarei aqui de sujeito-corpo-discursivo que (in)visibiliza(-se) na arte contemporânea, como um ritual sujeito a falhas na interpelação ideológica. Corpo que, "significado pela arte, constitui-se em uma materialidade que não se deixa aprisionar em um funcionamento de discurso sobre", pois "não é um corpo portador de um discurso, mas sim, um corpo atravessado pelo Discurso, constituído de discursividades, confrontado em suas dimensões do Real, do Imaginário e do Simbólico” (NECKEL, 2014, p. 207).

É justamente na arte contemporânea que esse corpo discursivo ganha mais espaço de significação. Historicamente, é na arte do século XX, conforme Michaud (2011, p. 558), que "o próprio corpo se torna um meio artístico: passa da condição de objeto da arte para a de sujeito ativo e de suporte da atividade artística". No decorrer de tal século, há, assim, ainda segundo a autora, "uma des-realização das obras em benefício do corpo enquanto 
veículo da arte e das experiências artísticas"10. A questão é que, como afirma Pêcheux (1997c, p. 257), "não se rompe jamais com a ideologia em geral, mas sempre com esta ou aquela formação ideológica, inscrita históricomaterialmente no conjunto complexo das formações ideológicas de uma formação social dada".

\section{Dobramentos Finais de um Percurso (em) Aberto}

Neste texto, me propus, na relação entre Arte e Linguística como áreas do conhecimento, e do lugar de analista de discurso, problematizar os sentidos possíveis para o sujeito na/da arte contemporânea, que se constitui e transita entre a estabilização e o movimento de sentidos nos entremeios dos discursos artístico e sobre o artístico. Arte esta que, como afirma Rivera (2013, p. 120), "agencia intervenções críticas na cultura, convidando a experiências de subversão - e de reflexão sobre o sujeito e o mundo, entrecruzando-se com a psicanálise e a filosofia, entre outros campos do saber".

Nessa e por essa possibilidade aberta no/pelo entremeio de áreas e dos discursos artístico e sobre o artístico, nesse entrelaçamento de perspectivas teóricas, que foi possível indagar - por intermédio da categoria da contradição - acerca do sujeito, como sujeito-corpo-discursivo (in) visibiliza(n)do(-se) na arte contemporânea.

O que fica desse percurso teórico são rastros de indagações, muito mais do que encontro de respostas, acerca desse sujeito, na/da arte contemporânea, descentrado, dividido, resultado da interpelação ideológica, dito e que (se) diz nessa arte, transitando entre a estabilização e o deslizamento

\footnotetext{
${ }^{10}$ Ferreira (2013b, p. 81) aborda o corpo na arte, funcionando como "objeto de intervenção artística" e "ferramenta dessa intervenção", ao se referir ao trabalho da artista plástica francesa Orlan, que tem atuações em Paris, Nova Iorque e Los Angeles. A artista é conhecida pela série de intervenções cirúrgicas estéticas em seu rosto, como movimento performático. A posição artística e ideológica de Orlan "não é contra intervenções plásticas, mas contra os padrões de beleza e o domínio destas ideologias que se entranham cada vez mais na carne dos homens e mulheres, numa sociedade que valoriza e idolatra a juventude" (FERREIRA, 2013b, p. 81).
} 
de sentidos. Sujeito inquietante, tal como a arte contemporânea em que se constitui sujeito... à língua, à história.

Para instaurar um rastro momentâneo de término do meu dizer, trago uma citação de Rivera (2013, p. 254), quando se refere ao trabalho artístico de Ernesto Neto:

Se topos é lugar, em grego, a topologia não é a ciência da localização, mas o estudo do fato, desnorteador, da falta de um lugar predeterminado para o sujeito. Poderia ter ele ainda alguma casa? Talvez a arte seja sua casa, só ela, efêmera em suas ações. Não o museu, em sua concretude arquitetônica e institucional, mas, às vezes, o que se passa ali (e pode se passar em qualquer parte).

É, portanto, inserindo-me no interior da área de Arte, e não fora dela - relembrando novamente Pêcheux (1990) quanto à resistência ser possível no interior do próprio movimento, não em lugar de lados opostos -, e do lugar de analista de discurso, cujo objeto de investigação é antes discursivo, que busco pensar e compreender a arte como discurso.

Parafraseando também Pêcheux no seu texto "Reflexões sobre a situação teórica das Ciências Sociais e, especialmente, da Psicologia Social"11 - assinado com o pseudônimo de Thomas Herbert, em 1966 -, para que o objeto de uma ciência possa ser metodicamente reproduzido, antes é preciso que a ciência à qual ele pertença o enuncie. Só que, desde que a ciência enuncie tal objeto, "ela é levada a confrontar seu discurso com ele mesmo para provar sua necessidade", e como "não basta que uma ciência fale, é preciso também que ela se ouç falar" (HERBERT, 2011, p. 49, grifos do original).

O objeto da teoria da Análise de Discurso é o discurso. "Objeto teórico", enfatiza Orlandi (2012). Por meio dele, é possível construir diversos objetos discursivos de análise. E é justamente essa possibilidade de construção de objetos discursivos múltiplos pela observação da/na área da Linguística e/ou de dentro dela, na circulação e observação de outras áreas do

${ }^{11}$ Texto assinado por Thomas Herbert, originalmente publicado em Cabiers pour l'analyse, 2, 1966, p. 174-203, conforme consta em rodapé no livro Análise de Discurso: Michel Pêcheux, em que foram reunidos textos do filósofo escolhidos por Orlandi (2011). 
conhecimento, como as Artes, que se tornou possível falar em Discurso Artístico, por uma abordagem materialista discursiva. "E se o discurso é uma materialidade histórica sempre já dada, na qual os sujeitos são interpelados e produzidos como 'produtores livres' de seus discursos cotidianos, literários, políticos, científicos, estéticos etc.", afirma Orlandi (2013, p. 24, grifos da autora), "a questão primordial cessa de ser a da subjetividade produtora de discurso e torna-se a das formas de existência histórica da discursividade".

\section{Referências}

ALTHUSSER, L. Resposta a John Lewis. In: ALTHUSSER, L. Posições I. Rio de Janeiro: Graal, 1978. p. 15-51.

BALDINI, L.; MARIANI, B. O real é o nome que se dá ao inominável. In: INDURSKY, F.; FERREIRA, M. C. L.; MITTMANN, S. (Org.). O acontecimento do discurso no Brasil. Campinas: Mercado de Letras, 2013. p. 103-114.

BORBA-RODEGHER, P. L. O tangenciamento do real pelo ato da nomeação. In: INDURSKY, F; FERREIRA, M. C. L.; MITTMANN, S. (Org.). O acontecimento do discurso no Brasil. Campinas: Mercado de Letras, 2013. p. 115-125.

CATTANI, I. B. Arte contemporânea: o lugar da pesquisa. In: BRITES, B.; TESSLER, E. (Org.). O meio como ponto zero: metodologia da pesquisa em Artes Plásticas. Porto Alegre: Ed. da UFRGS, 2002. p. 35-49.

CATTANI, I. B. Mestiçagens na arte contemporânea: conceito e desdobramentos. In: CATTANI, I. B. (Org.). Mestiçagens na arte contemporânea. Porto Alegre: Ed. da UFRGS, 2007. p. 21-34.

CAUQUELIN, A. Arte contemporânea: uma introdução. Tradução Rejane Janowitzer. São Paulo: Martins Fontes, 2005a.

CAUQUELIN, A. Teorias da arte. Tradução Rejane Janowitzer. São Paulo: Martins Fontes, 2005b. 
FERREIRA, M. C. L. Discurso, arte e sujeito e a tessitura da linguagem. In: INDURSKY, F.; FERREIRA, M. C. L.; MITTMANN, S. (Org.). O acontecimento do discurso no Brasil. Campinas: Mercado de Letras, 2013a. p. 127-139.

FERREIRA, M. C. L. O corpo como materialidade discursiva. Redisco, v. 2, n. 1, p. 77-82, 2013b.

FERREIRA, M. C. L. O corpo enquanto objeto discursivo. In: PETRI, V.; DIAS, C. (Org.). Análise de Discurso em perspectiva: teoria, método e análise. Santa Maria: Ed. da UFSM, 2013c. p. 99-107.

HERBERT, T. Reflexões sobre a situação teórica das ciências sociais e, especialmente, da psicologia social. Tradução Mariza Vieira da Silva e Laura A. Perrela Parisi. [1966]. In: ORLANDI, E. P. (Org.). Análise de Discurso: Michel Pêcheux. Textos escolhidos por Eni Puccinelli Orlandi. Campinas: Pontes, 2011. p. 21-54.

LAGAZZI, S. Análise de Discurso: a materialidade significante na história. In: RENZO, A. D.; MOTTA, A. L. A. R.; OLIVEIRA, T. P. (Org.). Linguagem, história e memória: discursos em movimento. Campinas: Pontes, 2011. p. 275-290.

LAGAZZI, S. O discurso em diferentes territórios: o vermelho entre todas as cores. In: MALUF-SOUZA, O. et al. (Org.). Discurso, sujeito e memória. Campinas: Pontes, 2012. p. 133-146.

MALUF-SOUZA, O. A concepção de sujeito lacaniano: um retorno paradoxal ao cartesianismo. In: MARIANI, B.; MEDEIROS, V. (Org.). Discurso e... . Rio de Janeiro: 7Letras; Faperj, 2012. p. 160-178.

MARIANI, B. Análise do discurso e psicanálise. In: MARIANI, B.; MEDEIROS, V. (Org.). Discurso e... . Rio de Janeiro: 7Letras; Faperj, 2012. p. $50-58$.

MICHAUD, Y. Visualizações: o corpo e as artes visuais. In: CORBIN, A.; COURTINE, J.-J.; VIGARELLO, G. (Dir.). História do corpo: as mutações 
do olhar - o século XX. 4. ed. Tradução Ephraim Ferreira Alves. Petrópolis: Vozes, 2011. p. 541-565. 3v.

NECKEL, N. Tecedura e tessitura do discurso artístico da/na produção audiovisual: materialidades fronteiriças. In: INDUSKY, F; FERREIRA, M. C. L.; MITTMANN, S. (Org.). O discurso na contemporaneidade: materialidades e fronteiras. São Carlos: Claraluz, 2009. p. 107-116.

NECKEL, N. O corpo-imagem: materialidade discursiva e práticas de subjetivação. In: TASSO, I.; SILVA, E. (Org.). Lingua(gens) em discurso: a formação dos objetos. Campinas: Pontes, 2014. p. 187-210.

NORONHA, M. P. Uma história tradicional. Duas pequenas parábolas da arte. In: NORONHA, M. P.; BATISTA, S. T. Essa tal arte contemporânea. Goiânia: América, 2012. p. 21-66.

NUNES, J. H. Discursividades contemporâneas e dicionário. In: INDUSKY, F.; FERREIRA, M. C. L.; MITTMANN, S. (Org.). O discurso na contemporaneidade: materialidades e fronteiras. São Carlos: Claraluz, 2009. p. 99-106.

ORLANDI, E. P. Efeitos do verbal sobre o não-verbal. Rua, Campinas, n. 1, p. 35-47, mar. 1995.

ORLANDI, E. P. As formas do silêncio: no movimento dos sentidos. 4.ed. Campinas: Editora da Unicamp, 1997.

ORLANDI, E. P. Análise de Discurso: princípios e procedimentos. 2. ed. Campinas: Pontes, 2000.

ORLANDI, E. P. Discurso e texto: formulação e circulação dos sentidos. Campinas: Pontes, 2001.

ORLANDI, E. P. (Org.). Análise de Discurso: Michel Pêcheux. Textos escolhidos por Eni Puccinelli Orlandi. Campinas: Pontes, 2011.

ORLANDI, E. P. Análise de discurso, ciência e atualidade. In: INDURSKY, F.; FERREIRA, M. C. L.; MITTMANN, S. (Org.). O 
acontecimento do discurso no Brasil. Campinas: Mercado de Letras, 2013. p. $17-30$.

PÊCHEUX, M. Delimitações, inversões, deslocamentos. Tradução José Horta Nunes. Cadernos de Estudos Lingüísticos, Campinas, n. 19, p. 7-24, jul./ dez. 1990.

PÊCHEUX, M. Análise Automática do Discurso (AAD-69). Parte I: Análise de conteúdo e teoria do discurso. In: HAK, T.; GADET, F. (Org.). Por uma análise automática do discurso: uma introdução à obra de Michel Pêcheux. 3. ed. Tradução Bethania Mariani et al. Campinas: Editora da Unicamp, 1997a. p. 61-105.

PÊCHEUX, M. O Discurso: estrutura ou acontecimento. 2. ed. Tradução Eni Puccinelli Orlandi. Campinas: Pontes, 1997b.

PÊCHEUX, M. Semântica e discurso: uma crítica à afirmação do óbvio. 3. ed. Tradução Eni Puccinelli Orlandi et al. Campinas: Editora da Unicamp, 1997 c.

PIMENTEL, R. M. L. Versões de um ritual de linguagem telejornalístico. 2008. Tese (Doutorado em Linguística) - Universidade Estadual de Campinas, Campinas.

PIMENTEL, R. M. L. A materialidade verbal-visual dos telejornais. In: SILVA, T. D.; SOUZA, T. C.; AUGUSTINI, C. (Org.). Imagens na comunicação e discurso. São Paulo: Annablume; Belo Horizonte: Fapemig, 2012. p. 181-209.

RIVERA, T. Arte e psicanálise. Rio de Janeiro: Zahar, 2002.

RIVERA, T. O avesso do imaginário: arte contemporânea e psicanálise. São Paulo: Cosac Naify, 2013.

SOUZA, T. C. C. de. Discurso e imagem: perspectivas de análise do não verbal. Ciberlegenda, Rio de Janeiro, n. 1, p. 1-10. 1998. Disponível em: < http://bit.do/cURGx>. Acesso em: 12 maio 2015. 
SOUZA, T. C. C. de. A análise do não verbal e os usos da imagem nos meios de comunicação. Ciberlegenda, Rio de Janeiro, n. 6, p. 1-43, 2001. Disponível em: <http://bit.do/cURGo>. Acesso em: 12 maio 2015.

ZAMBONI, S. O paradigma em arte e ciência. In: PILLAR, A. D. et al. Pesquisa em Artes Plásticas. Porto Alegre: Editora da UFRGS; Associação Nacional de Artes Plásticas, 1993. p. 29-38.

Recebido em: 30/05/2015 Aceito: $20 / 10 / 2015$ 